\title{
Dialektiline Harald Peep
}

\author{
PEETER OLESK
}

Filoloogiadoktor (Tartu, 1970, kinnitatud Moskvas 1971) Harald-Heino Peep (1931-1998) oli Tartu ülikooli eesti kirjanduse ja rahvaluule kateedri juhataja aastail 1966-1980, väliskirjanduse kateedri juhataja aastail 1980-1992 ja kirjandusteooria professor ülikooli filosoofiateaduskonnas alates 1992. aastast kuni oma ootamatu surmani Jyväskyläs. Neile küllalt vähestele, kes pääsesid teda lähemalt tundma, kuulus tema dialektilisus sõna antiigiaegses tähenduses igapäisesse kogemusse.

Harald Peebu dialektilisus avaldus ennekõike õppetöös, sest selles oli ta vabam kui artiklites, mida kammitsesid lugejaskonna ebamäärasus, toimetajate preskriptsioon ja paraku ka tellimused mitmeteks seisukohavõttudeks ning arutluskäikudeks. Ta enese ettevalmistus dialektilise vaatlusviisi omandamisel teaduses sündis peamiselt väljaspool filoloogilist kultuuri, nimelt retoorikas ja elokventsis kreekakatoliku kiriku liturgiliste tavade ning kommete järgi, niisiis selle põhjal, mida oli talle Valgas õpetanud emapoolne vanaema. Üht liini pidi olid Harald Peebu esivanemad pärit Rämedalt, teistpidi Peterburist. Oma emapoolset vanaisa Harald Peep ei mäletanud. Vanaema seevastu küll, sest vanaema äraostmatu sõltumatus oli talle vahest esmaseim eeskuju.

Koduse kasvatuse saigi Harald Peep just vanaemalt, kuna üleajateenijast isa Herbert Peep (1903-1938) suri, kui vanem poeg oli kõigest 7-aastane, liiati oli isa viimase eluaasta teeninud kodust eemal Tapal. Harald Peebu ema Niina (1912-1999) töötas telefonistina ning oli kakskeelne. Harald Peep ise kakskeelne ei olnud ja ma kaldun arvama, et tema vene keel oli vanaema kaudu pigem tsaari- kui nõukogudeaegne. Mitte vananenud, vaid gribojedovlik, idioomirikas ja alltekstirohke. Häälikute erinevuse eesti keeles, Lõuna-Eestile iseloomulikus mitmekeelsuses, tsaariaegses Peterburi vene keeles ja liturgilises kirikuslaavi keeles õppis ta ära arvatavasti üsna varakult. Kodust pidi ta saama ka retoorika alused, sest vanaema jaoks oli juba usuliste veendumuste tõttu tähtis, et väike poiss teaks, kuidas pöörduda kellegi poole ka siis, kui seda kedagi pole füüsiliselt kõrval; missugused on aupaklikud, missugused aga hereetilised või lausa jumalakartlikud kõnetlusvormid; mis on bütsantslik, mis kiievlik, mis moskvalik, mis vanausuline ning mis Tallinna- ja kogu Eestimaa-pärane. Oma õigeusklikkusega Harald Peep ei hoobelnud. Ta järgis oma kasvatust, näiteks nõnda, et keelas semutsemise iseendalegi ega leppinud sellega ka teiste juures. Tema oli lüüriline sissepoole. Vahest oli just see üks põhjusi, miks ta ei tahtnud kuuluda rektor Arnold Koobi (1922-1988) siseringi. Ta oli küllalt kõrge eneseväärikustundega juhtiv õppejõud ja samal ajal piisavalt kogenud psühholoog selleks, et näha läbi siseringi liikmete eripalgelisus. Ma ei tea nende hulgas kedagi, keda Harald Peep oleks nimetanud oma heaks sõbraks, isegi kui mõni neist oli ta põlvkonnakaaslane. 
Retoorika oli Harald Peebu jaoks kõnelemisviis ja kõne ehitus, mitte kõne ise. Selle põhjus oli väga lihtne: enamik ta kõnesid olid loengud üleskirjutajatele, mitte kuulajaile. Vastasel korral olnuksid need kohtukõned ja invektiivid. Dialektika oli aga arutlus-, mitte kõnelemisviis, selles oli enesestmõistetav põhimõte pro et contra või audiatur et altera pars. Olles invektiivide suhtes pigem irooniline kui sarkastiline, eelistas Harald Peep dialektikas rohkem Rooma protsessiõigust kui absolutistlikku preskriptsiooni XVII sajandi vaimus.

Ülikoolis tuleb sageli ette, et loeng või seminariettekanne on mingi teadusliku tulemuse esmane või koguni ainuline esitamise viis. Olukorda aforistlikult kirjeldades: artikkel võib ilmuda, ent loeng peab toimuma. 1960. aastatel loodi kujutelm, et pärast nn akadeemilise eesti kirjanduse ajaloo köidete ilmumist aastail 1965-1991 on eesti kirjanduse ajaloo õpetamine kõrgkoolides oluliselt hõlpsam. Õnneks mõeldi kõrgkoolides teisiti ja nii olid loengud köidete sisust koguni mitukümmend aastat ees kuni selleni välja, et oma kursustel keelas siinkirjutaja üliõpilastel nendele köidetele toetumise üldse ära. Üliõpilane pidi lugema uurimusi, mitte nende küsitava väärtusega ümberjutustusi!

Harald Peep otsustas enda üle suurel määral leivateenistuse põhjal. Seda ka siis, kui leib oli kibe. Ta teadis võrdlemisi täpselt, mis on tema rida ja ala, ning kuigi talle ei meeldinud, kui keegi ajas read ja vaod ja alad segamini, ei läinud ta ka omatahtsi „teise ritta” ehk distsiplinaarselt võõrsile. Õppetöö kõrvalt töötas ta pikka aega niisuguse administratiivse administraatorina, kelle kõrgeim foorum oli kuulumine Tartu ülikooli nõukokku. Sellest allpool oli ta kahel korral (1973-1976 ja 1984-1989) dekaan, aga mitte NLKP teaduskondlik sekretär ehk partorg, nagu siis öeldi. Kõigest ühel korral täitis ta parteilasena - nagu siis samuti öeldi - erakorralist ülesannet. Nimelt pidi ta 1973. aastal juhatama partei algorganisatsiooni koosolekut, kus võeti NLKP liikmeks saksa filoloogia kateedri juhataja dotsent Juhan Tuldava (1922-2003). Keegi (ma ei tea, kes) kartis, et liikmekandidaadile võidakse esitada küsimusi ta mineviku kohta. Nii öeldigi Harald Peebule enne koosoleku algust, et koosolekut juhatab tema, sest küllap ta oskab raskeid küsimusi kas ennetada või neid mujale suunata.

Maakeelse hariduse sai Harald Peep omasugustega tänaval mängides, Sangaste kandis karjas käies ja Valga gümnaasiumis. Viimasest pärinesid ta korralikud algteadmised ladina keele fraseoloogiast. Korralikud ses mõttes, et ta ei lubanud enesele ega teistelegi poolikuid fraase, vaid pidas loomulikuks, et fraas öeldaks välja lõpuni ning ütleja mõistaks ka fraasi konteksti. Teatri-saksa keele ja sakslaste ühiskeele murdeliste iseärasustega eriti leksikas tutvus ta Berliinis 1956. aastal, kui oli seal pool aastat rakkes süsteemis, mille ülesandeks oli propaganda „kodumaale tagasipöördumiseks". Propaganda väliseks vormiks olid petlikud raadiosaated ja vestlused inimestega, kes ei osanud lääne okupatsioonivägede kontrollitud Saksamaal ega üldse Läänes veendumuslikult käituda, kuna nad polnud seal varem käinud. Sõit sinna oli täiesti salajane, täpset sihtkohta ega ülesannet ei teadnud isegi Harald Peebu ema. Hiljem ei teinud pärastine professor oma lähetusest mingit hoolega varjatud saladust ja kuna tollane Berliin oli veel ilma müürita, siis on usutav, et ta tõepoolest tahtis parandada oma saksa keele oskust keset elavat keelt erisuguses keskkonnas. 
Ent igapäevase töö tegelikust sisust ja sõjajärgse Saksamaa argipäevast ning inimeste laialipaisatusest polnud tal mingit ettekujutust. Alles kohapeal selgus, mida ta seal peab tegema ning mismoodi seda kontrollitakse. Esimest korda mikrofoni ette istudes kujutles ta, et eeter on vaba, kuid juba järgmisel päeval ütles talle üks ülemusi, et nii see ei ole: eeter on kinnine.

Muide, omal algatusel ei rääkinud Harald Peep kunagi sellest, millise ettevalmistuse ta Saksamaal töötamiseks sai. Arvatavasti toimus see ajupesu vormis, järelikult mitte Tartus, ja ilmselt oli noor Harald Peep rahvusvahelise poliitika vallas märksa hoolsamalt haritud kui eesti kirjanduse ajaloos või poeetikas.

Rahvusvaheline poliitika sugenes meiegi kahemehevestlustesse ajavahemikul perestroika lõpust kuni akadeemik Jevgeni Primakovi (1929-2015) teenistusaja (1991-1996) lõpuni Vene Föderatsiooni Välisluureteenistuse juhina. Meie lugemisväljad ei kattunud. Professor Harald Peep ei jälginud nn keskajalehtede Pravda ja Izvestija igapäevast sisu, ei käinud Moskvas ega tollases Leningradiski. Ometi pani ta hoolega tähele, mismoodi käitusid perestroika ideelised juhid, kellest vanim oli akadeemik Aleksandr Jakovlev (1923-2005), noorim aga KGB tegevuse radikaalne ümberkorraldaja kindralleitnant Vadim Bakatin (snd 1937). Tähelepanemist reetsid Harald Peebu lakoonilised märkused ühe või teise kohta ja need ei olnud tsitaadid, vaid tema mõtiskluste kokkuvõtted. Rahvusvaheline poliitika oli tema jaoks ennekõike Venemaa julgeolekupoliitika Lääne suunal, peaküsimuseks mitte „mis meist (või neist) saab?”, vaid hoopis „mis saab inimestest?” ja alates 1993. aasta suvest ka „mis saab Eestis elavatest mitte-eestlastest?”. Eurointegratsiooni ta ei süvenenud, majanduspoliitilised tõsiolud olid tema jaoks „teiste rida” ning väliskapitali ekspansiooni tarvilikku statistilist andmestikku ta justkui pelgas.

Umbes niisugune oli see vaimne ümbrus, milles me Harald Peebuga ta elu viimasel kümnendil vestlesime põhjalikumalt kui jutujätkuks, harilikult ta töötoas. Tema istus oma massiivse kirjutuslaua taga, mina pisut kulunud diivanil. Meie vahele jäi pakk suitsu ja neli jahedat õlut.

Nood vestlused polnud kunagi kavandatud koduseks eriseminariks - alustuseks teema, vahepeal materjali läbitöötamine kokkulepitud ulatuses ja lõpuks ettekanne. Muidugi me lugesime teineteise trükis ilmunud töid, ent, välja arvatud minu neljanda õppeaasta kursusetöö ja diplomitöö, me ei arutanud neid ette ning ka hilisemad kommentaarid olid kas väga napid või polnud neidki. Arvatavasti tuli meil kirjanduse uurimise tõeline sisu jutuks juba 1975. aasta kevadel, põhjuseks professor Villem Alttoa monograafia „Eduard Vilde sõnameistrina” (1973). Olin seda lugenud kohe ilmumise järel ja ka arvustanud, nagu olin kirjutanud Vildest juba 1972. aasta sügisel. Professor Harald Peep võttis riiulist oma eksemplari, näitas sõrmega kaanepaberile ning ütles umbes nõndaviisi: pealkiri tõotab uurimust Vilde kui ilukirjandusliku sõna valdaja kohta, ent seda see monograafia ju ei ole! See on suurendus 1965. aastal avaldatud lühimonograafiast, mitte iseseisev Vilde poeetika käsitlus. Et lühimonograafia oli tekitanud küllalt temperamentse poleemika (August Palm, Villem Alttoa ja Nigol Andresen), oli meil mõlemal muidugi meeles, aga samuti oli selge, et uus raamat lubas üht ja pakkus teist, vaatamata sellele, et Villem Alttoa lühi- 
monograafia oli võrreldamatult elavam kui sarja „Eesti kirjamehi” varasemad osad ning ta väitekiri August Kitzbergist (1960).

Meie Vilde-alase vestluse käigus ei esitanud Harald Peep mingit iseseisvat poeetikatõlgendust. See, mis allpool järgneb, on rekonstruktsioon. Teda huvitas poeetiliselt rakendatud sõna saatus ennekõike ajalooliste parameetrite järgi ja selliste rakenduste klassifitseerimine sõltuvalt teose vormist tähenduses 'kompositsioon', modaalsusest (näiteks pilge või iroonia), autori taotlustest (näiteks nende taotluste dünaamika Henrik Visnapuul), tähenduse ülekannetest (vt Peep 1992: 21-37), kuid ka olenevalt sõna asukohast kunstilises tekstis (näiteks Gustav Suitsu lõppriimi „ideaalsus” või nooremapoolse Uno Lahe vokaalide positsiooniline järjestamine) või koguni sõna morfoloogiliste osade poeetilisest koormusest (probleem, mida on hiljem uurinud professor Huno Rätsep). Miks just sõna, mitte aga näiteks häälikud või poeetiline kompositsioon tervikuna (tundus, et Harald Peep kasutas väga harva sõnu struktuur ja kontekst)? Seepärast, et neil ajul, mil tema oma hariduse sai, polnud käepärast ainsatki normatiivset käsiraamatut nende keelte kohta, millega ta kokku puutus. Normi andis ette õpetaja rolli sattunud isik, kelleks näiteks Valga gümnaasiumi vene keele tundides oli umbkeelne juuditar. Liturgiline keel kehtestas ühed, venekeelsed uurimused teistsugused, professor Johannes Voldemar Veski kolmandad, Berliin neljandad, kaastöö Eesti ajakirjandusele viiendad normid. Ma ei märganud, et Harald Peebul oleksid need normid omavahel segi läinud. Oma poeetika süsteemi tuletas ta peamiselt XX sajandi esimese poole eesti luule põhjal, Gustav Suitsust kuni arbujateni. Sõna ise ei pruukinudki olla neologism, nagu seestumus, või murdepärasus, nagu üitsainus, või autorile ainuomane, nagu alumiiniumtagapõhjal ja kipjatokk. See võis vabalt olla ka kõige tavalisem, nagu kevad. Olulisem kui sõna leksikoloogilised parameetrid oli Harald Peebu jaoks sõna profileerimine poeetiliseks kas sõnaühendis, värsis, siirdes, lauses, perioodis või sõltuvalt sellest, kuidas muutuvad kunstilises tekstis kõneviis ja kõneleja vaatepunkt.

Pean üsna usutavaks, et ta mõtles ligikaudu järgmiselt: kuna me ei pääse ühemõtteliselt selgitama, mida kirjanik oma sõnaloomingus mõtleb, st kui ratsionaalne protsess see on, siis on suur saavutus seegi, kui oskame sõna poeetilist saatust kirjeldada vähemasti ühe kunstilise teksti piires. Nii paigutub Harald Peebu käsitlus mõistereas ilukirjanduse keel - stilistika - poeetika ridade vahele, täpsemateks koordinaatideks rahvakeel, kõnekeel, retooriline ehk elokventne keel, lavakeel, selektiivselt sihitud keel (näiteks diplomaatias), kirjakeel. Juba alates 1960. aastate lävelt oli see kõik nii akadeemiline kui ka distsiplinaarne probleem, sest stilistika tuli suruda sääraste ainete alla nagu „sissejuhatus kirjandusteadusesse” ja „kirjandusteooria koos marksistlik-leninliku esteetika alustega” ilma praktikumideta ning poeetikast kui ühes tähenduses iseseisvast teadusest kõneldi möödaminnes.

Me ei fantaseerinud. Oli vaikimisigi mõistetav, kuidas poliitilised arengud toimuvad kiiremini, kui muutub akadeemiline inerts, ja kui IME-t ettevalmistades leidis selle lõppdokumendis oma koha ka põhimõte, et IME-lises Eestis on akadeemiline haridus koos kõrgemat järku teadusega vaba, siis polnud meie ümbruskonnas kedagi, kes oleks teadnud, mis on selle vabaduse sisu ja hind. 
1988. aastal rektoriks saanud üldzooloogia professor Jüri Kärner (1940-2010) alustas ülikooli rahvusvaheliste suhete taastamisest, kuid oma välismaiste kolleegide nõuannete elluviimiseks oli tal vaja lähemaid abilisi. Meid oli mitu, kuigi kõik koos ei pidanud me nõu mitte kordagi. Siinkirjutaja kui rektori nõuniku (0,5 kohta) ülesanneteks olid erakirjalikud vastused rektori erisugustele küsimustele, vabade kunstide professuuri rajamine, usuteaduskonna taastamine (vt Olesk 2011) - milles usuteadus apostliku õigeusu vallas jäi professor Sulev Vahtre (1926-2007) ettepanekul lahtiseks, sest me ei tahtnud tuua kreekakatoliku kiriku subordinatiivseid konflikte ülikooli seinte vahele -, filosoofiateaduskonna loomine mitme varasema teaduskonna ja akadeemiliste instituutide põhjal ning korralise professuuri aluste põhjendamine. Harald Peep jälgis seda osa mu pikast päevatööst kõrvalt ega sekkunud sõnagagi. Isegi mitte küsimuses, mis saab stilistikast kui interdistsiplinaarsest ainest, sest minu proponeeritud õppetoolide ning lektoraatide seas (Olesk 1991: 200) polnud seda iseseisva ainena märgitud. Põhimõtteks oli, et õppetoolis korraldab distsiplinaarset koormust kas vastava aine korraline professor või õppejõud, kes õppetooli haldab, ja kui tema ettepanek nõuab ressursside ümberjagamist, siis otsuse langetab kas teaduskonna nõukogu või vaieldavuste korral ülikooli nõukogu, mitte aga Vabariigi Valitsus parlamendi ettepanekul või Vabariigi President ülikooli nõukogu soovil.

Rektor Jüri Kärner lähtus kolmest arusaamast. Esiteks oli selge, et nõukogudeaegne teaduse ja kõrghariduse rahastamise kord ei toimi ega või ka taastuda, sest Eesti Vabariik on rahvusvahelise õiguse järgi suveräänne riik. Teiseks, kujunenud olukorras tuleb Tartus koonduda võimalikult alma mater'i ümber, mis tekitas korraks lausa raevuka protestilaine, sest osa teadlaskonnast kartis väga sõltuvust pedagoogilisest pragmatismist eriti allpool doktoriõpet. Kolmanda arusaama sõnastas Jüri Kärner põhimõttena, et akadeemiline palve on õigupoolest käsk.

Mida võis sellest kõigest arvata professor Harald Peep? Küllap ta oli teist korda dekaan, kui sedastas, et dekaanide peamine kohustus rektoraadis ja ülikooli nõukogus on kaitsta oma teaduskonna huve, sest seda kohustust ei saanud delegeerida ei allapoole ega kõrvale. Dekaan koordineeris esmajoones õppetööd ning õppejõudude koormust iseäranis juhtudel, mil mingit ainet tuli lugeda „oma” teaduskonnast väljaspool (näiteks üldfüüsikat arstidele). Seevastu teaduslikuks tööks vajalike vahendite leidmine ja komandeeringud Eesti NSV-st väljapoole nõudsid teadusprorektori allkirja. Harald Peep oli koos kolleeg Karl Muruga millalgi 1960. aastate lõpul lootnud, et kui mõlemad jõuavad filoloogiadoktori kraadini, siis ühes sellega on nad eesti kirjanduse ajaloo uurimises määravamad kui mis tahes administratiivse ametikoha täitjad (Olesk 2001a, 2001b). Filoloogiateaduskonnas Tartus aga niisugust autonoomiat ei saavutatud.

Veel enne doktorantuuri astumist 1968. aastal arvas Harald Peep mitmes programmilises artiklis (vt Peep 1978: 5-6), et eesti kirjanduse ajaloo käsitlemine muutub süstemaatiliseks siis, kui see hakkab põhinema kirjanike uurimisel prot se ss i s, ajalises mõõtkavas ehk historistlikult vaatekohalt. Ta pidas õigeks pöörduda tagasi kirjanikule antud aja piiride ja nende omaksvõtmise juurde vormis, mille vahenditus oli/on tajutav intuitiivseltki, nimelt lüürikas. Akadeemilises õppetöös tähendas see vabariigiaegse kirjanduse esitamist eesti kirjanduse ajaloo üldkursuse 
loomupärase osana ning ilma nende quasi-kategooriateta, mis olid sätestatud mõistega Nõukogude paljurahvuseline kirjandus (6-köiteline koguteos pealkirjaga „Nõukogude paljurahvuselise kirjanduse ajalugu” ilmus Moskvas aastail 1970-1974), poeetikas aga selle seadmist esikohale, mida tookord, 1960. aastail, nimetati parema puudusel tundelüürikaks, uueks luuleks või isegi suureks luuleks. Kuna strukturaalne temaatiline analüüs ehk poeetilise teksti analüüs denotatiivsete semantiliste maatriksite kaupa (vt Chudakov 2016) oli Harald Peebule võõras, eelistas ta vooluloolisele vaatlusviisile mõneks ajaks Georg Brandese (1842-1927) moodi kirjandusele lähenemist esteetiliste põhitüüpide (klassitsism/romantilisus) järgi (Peep 1978: 84-85). Professor Juri Lotmani materjalikeskse käsitlusviisi ülekandmist eesti kirjandusloo arengu mõistmiseks Harald Peep ilmselt ei pooldanud. Rohkem rahuldas professor Harald Peepu arusaamine, et kirjanik asub juba loomuldasa korraloomise ja vabadusse pürgimise vahel, järelikult tuleb suuta vastata küsimusele, kus ta seal täpselt asub ja millised on selle asukoha koordinaadid. Poeetiline norm võib ju olla väga isikupärane (ehkki mitte alati kogu loomingut läbiv!), nagu Ain Kaalepil järvemaastikud (vt Olesk 1996), aga see võib olla ka vormipärane, nagu sonett (mida muide Kalju Lepik pidas konstruktsiooniks, mitte kompositsiooniks), või ajastuomane, nagu ajaluule, või koguni ajastuülene, nagu pühendusluule.

Nagu mainitud, eelistas Harald Peep klassitsismi/romantilisuse polaarsust vahest kuni doktoridissertatsiooni kirjutamise keskpaigani 1960. aastate lõpul. Seejärel leidis ta võimaluse minna edasi selle uurimises, kelle ja mille poole poeetilise pildi looja pöördub ning millest ta lähtub (Peep 1978: 9-17, 114-117). Mõnikord võis luuletaja lähtekohaks olla autobiograafiline aines, nagu Gustav Suitsul, Juhan Sütistel või Betti Alveril. Aga kui autobiograafiline oli näiteks Johannes Barbarus? Ning kust läheb piir enesetunnetuse ja ajastutunnetuse vahel niisugusel luuletajal nagu August Alle, kes alustas ju varjamatu enesekehtestamisega? Mitmel luuletajal tõmbas Nigol Andresen selle piiri eluloolise andmestiku, looduspiltide ja ühiskondliku närvitundlikkuse järgi. Teistsuguste luuletajate juures otsis Harald Peep sarnast piiri sõna kui adressaadi poole pöördumise vahendi juurest.

Veel 1960. aastate keskel oli Harald Peep veendunud, et kirjandust tuleb uurida probleemide järgi, mitte selleks eraldatud trükipoognate ulatuses (Peep 1966). Doktorantuur pani ta mõtlema teisiti. Tema päevanormiks sai lehekülg puhast teksti, ja kui see oli valmis, astus ta kõigepealt läbi Werneri maletoast ning seejärel Eesti NSV Kirjanike Liidu Tartu osakonnast professor Jüri Uluotsa majas. Sealgi mängiti malet. Harald Peebule meeldis välgutada, mida saatis aasiv jutuvada. Ta ei varjanudki uhkust seeüle, et esitas väitekirja „Eesti lüürika kujunemislugu aastail 1917-1929” (käsikirjas kaks köidet) kaitsmiseks enne oma 40. sünnipäeva, kuid ta tundis ka meelekibedust selle tõttu, et suured kirjandusloolised või ka teooriaalased ettevõtmised võeti käsile ilma tema eruditsiooni ja haardeta. Siis muutiski ta oma uurimisteemasid nõnda, et esikohale tõusid kirjandusliku protsessi käsitlemise meetodid, ehkki varem oli teda huvitanud mitte niivõrd meetod ise, kuivõrd see, mida on võimalik ühe või teise meetodi abil ära teha. Et mõistel meetod oli nõukogude kirjandusteaduses neli tähendust, see sai probleemiks omaette, kirjandusloole veelgi lisaks. 
Olgu kohe arvatud, et marksistlik meetod kirjandusteaduses oli Harald Peebu jaoks täiesti imaginaarne selle sõna arvuteoreetilises tähenduses. Ta ei osanud seda omaks pidada, veel vähem kavatses ta seda rakendada. Vastupidi: kui ta sooritas nn kandidaadimiinimumi eksami filosoofias, siis tegi ta seda läbi tõlgi, kelleks ta valis hilisema professor Mihhail Makarovi (1922-2019). Eksaminand ütles eesti keeles vaid mõne lause, mille tõlk arendas sealsamas terveks lõiguks ja kuna tõlk oli omas vallas tõepoolest erudeeritud, kujunes viimistletud tõlge vaieldamatult paremaks kui „algupärand” (ning arvatavasti ka eksamikomisjoni teadmised kokku). Harald Peebu stuudiumi kestes ja ta teadlasetöö esimesel poolel mõisteti meetodit nõukogude kirjandusteaduses valdavalt kunstilise meetodina (Peep 1967: 9-22) säärases hierarhilises reas, mis algas realismiga antiikaja keskel ja lõppes sotsialistliku realismiga kõikjal, kus tunnistati arenenud sotsialismi võitu vähemasti ühes riigis. Sellest võiks järeldada, et loomingumeetod oli Harald Peebu jaoks võõravõitu kategooria, kuna see eeldas kirjanikult väga ratsionaalset käitumist. Kui kasutada 1960. aastate algupoole kirjandusliku praktika käibesõnu, siis võiks öelda, et tollal nõuti kirjanduselt füüsikule iseloomulikku mõtlemist, milles kirjanduslik füüsik oli vormis klassitsistlikult konservatiivne (näiteks eepiline romaan) ja uuendaja vahest ainult teemades (näiteks Erni Krusteni „Vana võrukael”, 1966), ent lüürik oli novaator igas suhtes (näiteks Jaan Krossi kogu „Lauljad laevavööridel”, 1966).

1980. aastate künnisel jõudiski Harald Peep sõna kui kirjandusliku vahendi juurde, millest ta valis lähemaks uurimiseks poeetilise modaalsuse (neid sõnu kasutamata) ning selle muutumise. Filoloogiliselt poolelt huvitas teda sõna muutuv modaalsus morfoloogilise struktuuri kahes kihistuses - nii tüve ja liidete kui ka isoleeritud sõna ja selle süntaktilise positsiooni pinnal. Kuid mõlemal juhul huvitas teda ka see, kui suure täpsusega saab sõna modaalsuse muutumise varal kirjanduslikku protsessi liigendada, ükskõik siis, kas ajaliselt, autoriti või teoseti.

Pole teada, et Nigol Andresen, Ralf Parve või Harald Peepki oleks koostanud mingit metoodiliselt korrastatud kartoteeki poeetiliselt profileeritud sõnakasutuse kohta. Nad märkisid tekstist välja neid huvitavad sõna- või häälikukasutused ja noteerisid konkreetse uurimuse jaoks, kas leitud näited on paradigmaatilised või mitte. Kirjandusloolasena tegeles Harald Peep küsimusega, mida ütleb luuletaja sõnakasutus tolle aja kohta, mil ta elas - või ka ajatult. Selleks et seda kasutust illustreerida ja mitte rahulduda tekstikorpusliku dokumentatsiooniga, pidas professor otstarbekamaks otsida üles kas käänupunktid kirjaniku sõnaloomingus või nood määramispiirkonnad, kuhu kuulub mitme kirjaniku sõnalooming. Noore August Alle veendumuses pidi luuletaja olema rohkemat kui rebell, tema pärisosaks pidi olema võim (võib-olla konkreetsemalt vaimne võim). Harald Peebu käsitluses jätkas seda liini Betti Alver, tõenduseks luuletus „Vaim, kandes kord triumfipärgi” (1939). Alver ei kirjutanud küll välja, mis oli vahepeal juhtunud seesugust, et „nüüd vaim on vardas", ent ei jää kahtlust, et Allele oli võimu-usk ajutine, Alverile aga igiomane ettevaatlikkus võimu suhtes igal pool, kus see end mis tahes vormis ilmutab. See on koht, kus sõna kui lekseem võib küll püsida ühe ja sellesamana, ent ei jää samaks niipea, kui see läheb käänupunktist üle määramispiirkonda. Et jõuda ses suhtes suurema selguseni, pöördus professor Harald Peep tagasi biograafilise kirjanduskäsit- 
luse juurde - nagu tegid mitmed ta kolleegidki. Nii sündis sarjas „Eesti kirjamehi” kaua meeles kantud raamat „Henrik Visnapuu” (1989).

Hilisemal Harald Peebul - vanaks meheks ta ju ei elanudki - oli oma kodu otsatoas aega mõtiskeluks rohkem, kui nõudis akadeemiline õpetustöö tudengite ees seismisel. Retoorikat oli ta erinevalt paljudest teistest õppinud tundma süvemalt kui stilistiliste kõnefiguuride pealispind ning dialektiline arutluskäik inspireeris teda sealgi, kus tema kui kõneleva õppejõu vastas istuvad üliõpilased tegid oma märkmeid vaikides (professor ei dikteerinud loenguid). Akadeemilistest muredest lahendati professor Harald Peebu eestvedamisel see, et eesti kirjanduse ajalugu sai Tartu Ülikoolis taas eesti filoloogide erialase hariduse enesestmõistetavaks osaks. Kuidas seda osa hoida ja ülikooli akadeemilises struktuuris kinnistada, selles polnud Harald Peep sugugi kindel, sest kuigi ta pooldas lauset Tempora mutantur et nos mutamur in illis täies pikkuses, ei meeldinud talle üldsegi selle lause teine pool enese kohta. Distsiplinaarsetes vahekordades hoiti suurelt osalt ka tänu temale ära eesti kirjanduse lahustamine nõukogude kirjanduse sees. Venekeelne nõukogustamine tuli peatada ja see ei võinud olla ühekordne akt, et paned punkti ja ongi kõik.

Tänan südamest Külvi Pruulit, kes otsis välja Niina Peebu eluaastad.

Tähtvere mõisas 29. XII 2020

\section{KIRJANDUS}

Chudakov, Aleksandr 2016. Poetika Chekhova. Mir Chekhova: Vozniknovenie i utverzhdenie. Sankt-Peterburg: Azbuka-Attikus. [Александр Павлович Чудаков. Поэтика Чехова. Мир Чехова: Возникновение и утверждение. СПб.: Азбука-Аттикус.]

Olesk, Peeter 1991. Üksi koos teistega. Filoloogia õpetamisest teadusena. - Keel ja Kirjandus, nr 4, lk 193-204.

Olesk, Peeter 1996. Korrasõbra vabaduskiusatus. - Keel ja Kirjandus, nr 6, lk 364-365.

Olesk, Peeter 2001a. Autori mõistmiseks. - Harald Peep, Nii et suled lendavad. Kilde kirjanike poleemikakultuurist. Tartu: Ilmamaa, lk 153-160.

Olesk, Peeter 2001b. Luule omal kohal. - Karl Muru, Luuleseletamine. Tartu: Ilmamaa, lk 457-464.

Olesk, Peeter 2011. Ajalugu seestpoolt: kuidas taastati usuteaduskonda. - Eesti Kirik 18. V.

Peep, Harald 1966. Problemaatilist meie kirjandusloolises töös. - Keel ja Kirjandus, nr 4, lk 204-209.

Peep, Harald 1967. Pilk peegli taha ehk arupidamisi sõnakunsti teooria ja praktika üle. Tallinn: Eesti Raamat.

Peep, Harald 1978. Tähtraamat. Tallinn: Eesti Raamat.

Peep, Harald 1992. Hajamõtteid huumorist. Tallinn: Eesti Raamat.

Peeter Olesk (snd 1953), Eesti Kirjanduse Seltsi auliige (Vanemuise 19, 51014 Tartu), prouadoktor@gmail.com 


\section{Dialecticity in Harald Peep's literary studies}

Keywords: Harald-Heino Peep formerly Professor of Estonian Literary History and General Literary Studies at the university of Tartu, Socratic dialectic in literary studies, stilistics as a border area between traditional rhetoric, eloquence and poetics, topical problems in $20^{\text {th }}$-century Estonian lyrical poetry

Professor Harald-Heino Peep (1931-1998) was a long-time professor of the latest history of Estonian Literature at the university of Tartu. The main emphasis of his studies was on the literary process as shared creativity. Gradually, he also delved into the methods of studying literature, seeing their common part in following the fate of words applied figuratively in the works of poets connected only conditionally, if at all. This perspective was inspired by Socratic dialectic as it was understood in the 1960s, notably, as an attempt to dispense with postulative poetics in favour of historical poetics. The latter mostly involves mythopoetic thinking and its manifestations in early but also in medieval epics. Harald Peep changed the angle by juxtaposing the structure of an artistic text with parameters of a spoken text (e.g. of the text presenter's address to the audience). Accordingly, he treated topics not as poetic commonplaces but as a line of demarcation between the poet as the chosen one and the plebs (the common mob), where one of the tasks of the poet is judgement.

Peeter Olesk (b. 1953), Honorary member of Estonian Literay Society (Vanemuise 19, 51014 Tartu), prouadoktor@gmail.com 